\title{
POWER AND PARTICLE EXHAUST IN TOKAMAKS
}

by

R.D. STAMBAUGH

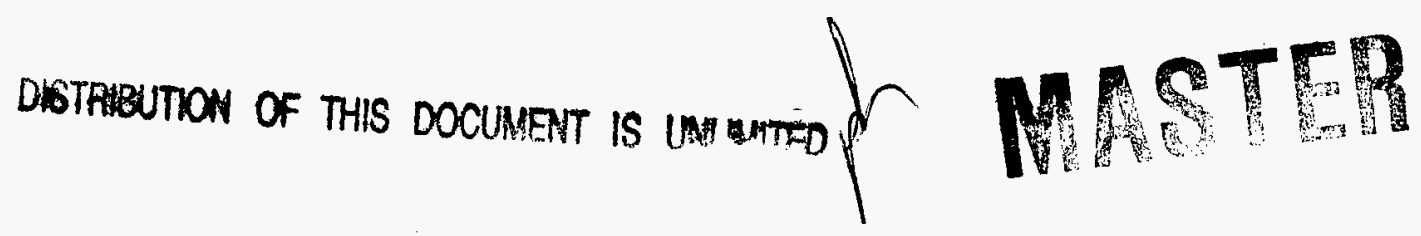

19980401052

3ECENED

FFR 101998

OSTI

JANUARY 1998

DIIC QUALITY IRTESETTED 3 
This report was prepared as an account of work sponsored by an agency of the United States Government. Neither the United States Government nor any agency thereof, nor any of their employees, makes any warranty, express or implied, or assumes any legal liability or responsibility for the accuracy, completeness, or usefulness of any information, apparatus, product, or process disclosed, or represents that its use would not infringe upon privately owned rights. Reference herein to any specific commercial product, process, or service by trade name, trademark, manufacturer, or otherwise, does not necessarily constitute or imply its endorsement, recommendation, or favoring by the United States Government or any agency thereof. The views and opinions of authors expressed herein do not necessarily state or reflect those of the United States Government or any agency thereof. 


\title{
POWER AND PARTICLE EXHAUST \\ IN TOKAMAKS
}

\author{
by \\ R.D. STAMBAUGH
}

This is a preprint of an invited paper presented at the 17th IEEE/NPSS Symposium on Fusion Engineering, October 6-10, 1997, San Diego, California, and to be printed in the Proceedings.

\author{
Work supported by \\ the U.S. Department of Energy \\ under Contract No. DE-AC03-89ER51114
}

\section{GENERAL ATOMICS PROJECT 3466 JANUARY 1998}




\title{
Power and Particle Exhaust in Tokamaks
}

\author{
R.D. Stambaugh \\ General Atomics, P.O. Box 85608, San Diego, California 92186-9784
}

\begin{abstract}
The status of power and particle exhaust research in tokamaks is reviewed in the light of ITER requirements. There is a sound basis for ITER's nominal design positions; important directions for further research are identified
\end{abstract}

\section{INTRODUCTION}

The status of power and particle exhaust in tokamaks is best summarized by examining the status of the world's tokamak database in its applicability to ITER. The ITER divertor provides quantitative definitions of the critical issues [1]. The ITER divertor must exhaust a major fraction of the alpha heating power ( $300 \mathrm{MW}$ nominal). The divertor physics solution sought should keep the peak power load on the divertor surface below $5 \mathrm{MW} / \mathrm{m}^{2}$. The divertor must exhaust the helium ash at its production rate in the main plasma $\left(5 \times 10^{20} \mathrm{He}\right.$ atoms/second $)$. The particle exhaust system must control the main plasma density as the primary mechanism of controlling the fusion power output of the machine. These power and particle control goals must be met while maintaining good confinement and acceptable impurity levels and edge densities. To maintain good energy confinement, it is expected that a low neutral density must be maintained near the main plasma while a high neutral density is maintained in the divertor region.

The approach taken to meeting these requirements in ITER is a deep slot single null divertor [1]. The distance from the $\mathrm{x}-$ point to where the divertor separatrix strikes the divertor plate is about $1.7 \mathrm{~m}$. A vertical target intercepting the separatrix and SOL field lines at a steep angle is presently the baseline option. The divertor slot is tightly baffled by the sidewalls to promote a high ratio of neutral pressure at the bottom of the slot to the neutral pressure near the main plasma. Gas seals in the divertor structures prevent bypass leaks of neutrals out of the divertor up to the main plasma. The pumping is done by ducts from the private flux region to external cryopumps $\left(170 \mathrm{~m}^{3} / \mathrm{s}\right)$. Carbon fiber composites are used in the high heat flux zones near the divertor strike points. Tungsten is used on other divertor surfaces where mainly neutrals impinge in order to avoid high chemical erosion. Beryllium is used on the main chamber first wall to provide only a low $\mathrm{Z}$ sputtering source to the main plasma. The entire design is contained in a remotely removable cassette which allows both maintenance and flexibility for future changes in the divertor configuration as suggested by the presently rapidly evolving experimental situation in regard to the optimal choice of divertor geometry.

\section{POWER EXHAUST REQUIREMENTS}

An upper bound on the power that must be exhausted in ITER can be estimated from the alpha power at the nominal operating point ( $300 \mathrm{MW}$ ), the possible simultaneous use of additional auxiliary heating power (100 MW), and a possible excursion of the burn point to $20 \%$ more alpha power $(60 \mathrm{MW})$. Altogether, one might envision a total of $400 \mathrm{MW}$ power. There will be about $100 \mathrm{MW}$ bremsstrahlung radiation from the ITER core plasma. Additionally, one might envision about $50 \mathrm{MW}$ impurity line radiation (a typical proportion of core impurity radiation to input power in the cleanest plasmas in current tokamaks). Hence about $250 \mathrm{MW}$ would cross the separatrix into the SOL and flow down the open field lines to the divertor plate. Considering a nominal $1 \mathrm{~cm}$ SOL fall-off length for parallel power flow, the plate inclination of the ITER divertor, both the inner and outer divertor, and the flux expansion at the target plates, a nominal target area of $10 \mathrm{~m}^{2}$ is available to receive the heat exhaust from the core plasma. Hence a power loading of $250 \mathrm{MW} / 10 \mathrm{~m}^{2}=25 \mathrm{MW} / \mathrm{m}^{2}$ would result. The engineering design target set at the start of the EDA was $5 \mathrm{MW} / \mathrm{m}^{2}$. Consequently a reduction in the parallel heat flow by a factor of five was demanded of the physics of the SOL and the divertor. The basic approach to the ITER divertor was then to intercept the parallel power flow by radiation from impurities and hydrogenic processes in order to effect the factor five reduction in parallel heat flux. The intercepted power was to be radiated onto the much larger area of the sidewalls of the divertor slot. Considering only the outer divertor slot, an area of about $300 \mathrm{~m}^{2}$ is available. If that area were uniformly illuminated by the $250 \mathrm{MW}$, an average power loading of $0.8 \mathrm{MW} / \mathrm{m}^{2}$ would result; hence a uniformity of the radiation in the slot of only $6: 1$ would suffice to maintain the peak heat flux below $5 \mathrm{MW} / \mathrm{m}^{2}$.

The nominal power balance case of ignited operation in ITER requires only the exhaust of $300 \mathrm{MW}$ of alpha power. After subtracting the $100 \mathrm{MW}$ bremsstrahlung and the clean core plasma case $50 \mathrm{MW}$ line radiation, and realizing that $50 \mathrm{MW}$ can flow onto the divertor plates, this nominal case sets a target of $100 \mathrm{MW}$ radiation to be achieved in the SOL/ divertor plasma. Driven burn scenarios might increase the total heating power to $400 \mathrm{MW}$. The easiest way to handle this increased power would be to radiate more in the plasma core (150 MW core radiation). Hence it is of interest to examine the basis for enhanced core radiation operating modes. However, the use of increased core radiation might

*Work supported by U.S. Department of Energy under Contract No. DE-AC03-89ER51114. 
be incompatible with core plasma dilution problems or with the requirement to allow sufficient power to cross the separatrix to stay in $\mathrm{H}$-mode. If the driven burn scenario had to be accommodated without increasing core radiation, then $250 \mathrm{MW}$ must be envisioned to flow into the SOL. There are two strategies for coping with this larger SOL/divertor power exhaust requirement. During the EDA the divertor plate design has evolved to be able to handle peak power loads of $10 \mathrm{MW} / \mathrm{m}^{2}$ (with some penalty in reduced erosion lifetime) so that $100 \mathrm{MW}$ could be allowed to flow to the divertor plates. In that case, or in the case where the increased divertor plate load is not taken, one desires that the SOL/ divertor plasma be able to radiate 150-200 MW of power. Physics approaches to produce such high levels of divertor radiation are desirable for operational flexibility in ITER.

\section{CORE RADIATION APPROACHES}

Two encouraging approaches to high core radiation operating modes emerged during the EDA, the CDH-mode first found in ASDEX-Upgrade and the RI-mode in TEXTOR. The $\mathrm{CDH}$ mode is achieved by careful, simultaneous deuterium and impurity ( $\mathrm{Ne}, \mathrm{Ar}, \mathrm{N}$ ) puffing controlled to give constant divertor neutral deuterium flux (and hence nearly constant mid plane separatrix density [2]) and a constant total radiated power fraction near $100 \%$. The neon preferentially radiates in a mantle just inside the separatrix ( $>70 \%$ radiation above the $x$-point). The power flow through the edge is kept at a level just above the $\mathrm{H}-\mathrm{L}$ threshold power, where the Type III ELMs appear; their power pulses to the divertor plates are very small. The power to the divertor plates reaches noise level and the divertor plasma completely detaches. Compared to $\mathrm{H}$-mode plasmas at lower densities (with type I ELMs), the edge confinement is somewhat reduced, but this is roughly compensated for by increased core confinement as a consequence of some density profile peaking. CDH-type radiative edge plasmas have been reproduced also in other divertor tokamaks [3]. The $Z_{\text {eff }}$ in the core plasma in this mode is high $\left(Z_{\text {eff }} \sim 3\right)$ in ASDEX Upgrade because neon is low Z; simulations for ITER using Argon or Krypton as the mantle radiator [4] have shown that sufficient core radiation can be achieved to get the power crossing the separatrix down to the L-H transition threshold power without incurring too large a core plasma $\mathrm{Z}_{\text {eff }}$. Provided the $\mathrm{L}-\mathrm{H}$ transition power can be low enough in ITER, this $\mathrm{CDH}$ regime operation appears to have no obstacles to use in ITER.

Recent work on the TEXTOR tokamak has demonstrated that discharges can be maintained for up to 100 energy confinement times using neon or silicon to produce a radiating mantle with little increase in central impurity accumulation [5]. These discharges were obtained using a pumped limiter geometry. These discharges reach densities just exceeding the empirical Greenwald density limit. Despite the high density and the radiation fraction approaching $100 \%$, the energy confinement time actually rises as the radiation fraction rises and reaches values exceeding the ITER-93H scaling for $\mathrm{H}$-mode. The $\mathrm{RI}$ mode has displayed the best combination of characteristics for operation for long pulse with nearly $100 \%$ radiation fraction at the Greenwald density limit and with good confinement. Further investigation of this mode is required in other and larger devices to establish its potential applicability to future machines.

\section{REDUCTION OF THE PEAK HEAT FLUX TO THE DIVERTOR PLATES}

Using a variety of techniques all divertor tokamaks have been able to reduce the peak heat flux to their divertor plates by almost the factor of five required as the essential concept of the ITER divertor. The extended radiating zone achieved in DIII-D is documented below; the accompanying reduction in peak heat flux is about a factor of 4 [6]. DIII-D finds a controllable reduction in peak heat flux generally in the range of a factor 4-5 using deuterium, neon, and argon gas puffing. JET has reduced the peak heat flux a factor of 4 using deuterium, neon, and nitrogen puffing [7]. JT-60U reports factor 3-4 reductions in peak heat flux using deuterium puffing with most of the radiation coming from intrinsic carbon [8]. ASDEX Upgrade has achieved the $\mathrm{CDH}$ regime using neon puffing in which the heat flux to the divertor plates is reduced to noise level in their instrumentation [2]. Alcator $\mathrm{C}$-mod has reported over a factor of 10 drop in plasma pressure along the separatrix field line using either deuterium, neon, or nitrogen puffing [9]. It would seem on the basis of these experimental results rather straightforward to achieve about a factor of 5 reduction in peak heat flux to the divertor plates.

\section{SPREADING THE HEAT LOAD ALONG THE DIVERTOR}

An example of a radiating divertor plasma in which the heat flux has been spread along the divertor leg to the extent required by ITER is afforded by a discharge from DIII-D (Fig. 1) [6]. The radiation produced by deuterium puffing is shown to be distributed evenly from the $x$-point region to the divertor target. The uniformity in radiation is approximately 2:1 and exceeds the requirements of ITER divertor design. Spectroscopy indicates that carbon radiation dominates in the $\mathrm{x}$-point region with deuterium radiation peaking near the target. The deuterium radiation arises because the plasma is recombining strongly in the lower portion of the divertor channel.

\section{SOL/DIVERTOR RADIATION CALCULATIONS FOR ITER}

The B2-EIRENE code has been used to calculate the achievable radiation in the ITER SOL/divertor plasma using neon as the seeded impurity [4). With $200 \mathrm{MW}$ total power into the SOL and an acceptable $0.7 \%$ concentration of neon, $115 \mathrm{MW}$ of radiation in the SOL/divertor was calculated and the power flow to the divertor plates was reduced to $55 \mathrm{MW}$ (outer target) and $30 \mathrm{MW}$ (inner target). The peak heat flux occurred on the outer target and was only $5 \mathrm{MW} / \mathrm{m}^{2}$. These computational results and the experimental successes at 

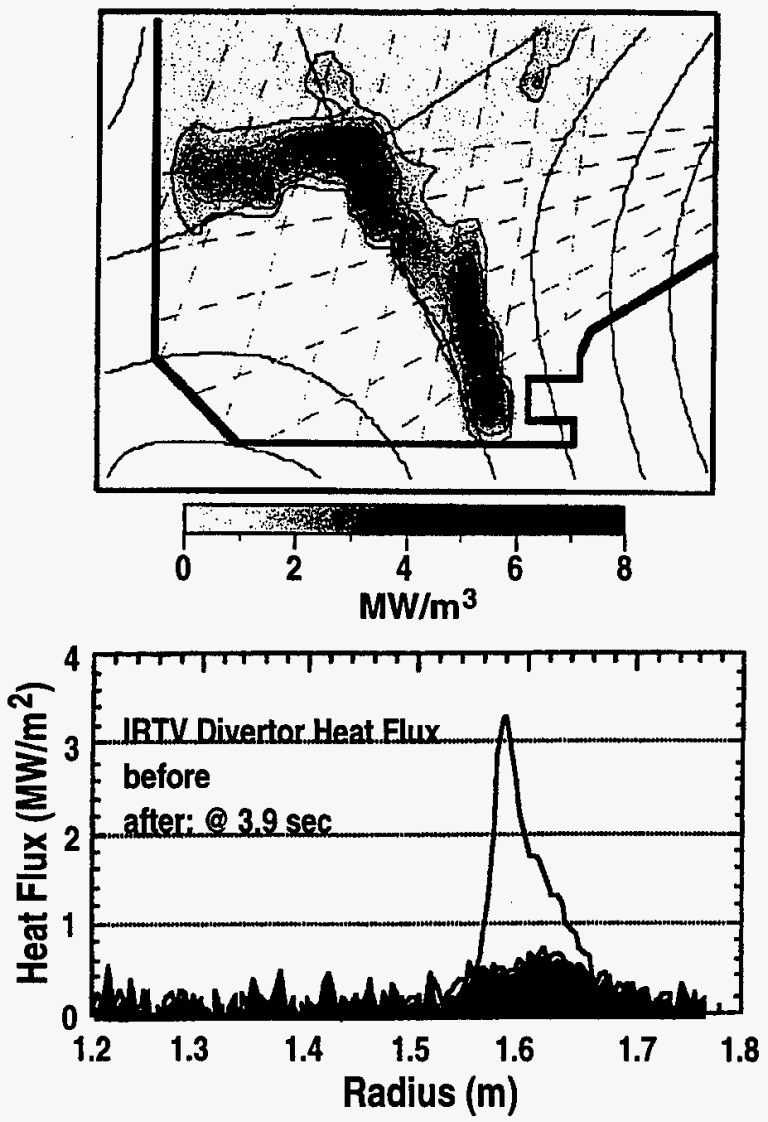

Fig. 1. The radiation distribution in a detached plasma in DIII-D produced by deuterium gas puffing. Also shown is the reduced heat flux at the divertor target..

reducing the parallel heat flow by a factor of five and spreading the radiation along the divertor leg provide a sound basis for ITER's nominal power balance position of $100 \mathrm{MW}$ radiation in the SOL/divertor.

\section{APPROACHES TO INCREASED DIVERTOR RADIATION}

A simple model of divertor physics implies an in-principle limitation to the radiation in the SOL/divertor for a given upstream density [10]. Early estimates from this model gave the nominal $100 \mathrm{MW}$ SOL/divertor radiation in ITER. Physics approaches to increasing the ability of the SOL/divertor plasma to radiate, perhaps up to the $200 \mathrm{MW}$ level in ITER are:

Impurity concentration enrichment in the divertor

Non-coronal equilibrium radiation rates

2-D flow patterns of heat and fuel

Non-Maxwellian enhancements of radiation

Classical drifts, $\mathrm{E} \times \mathrm{B}$, gradT $\times \mathrm{B}$

Plasma recombination

Perhaps the most striking element of these approaches to enhanced divertor power exhaust to emerge from experiments during the EDA has been the recent confirmation of stable plasma operational modes with high degrees of plasma recombination $(50 \%)$ in the divertor and large reductions in the ion flux and the plasma pressure at the targets. These detached plasma states have been thoroughly documented [11-15]. The 2-D codes predicted recombining solutions with $1 \mathrm{eV}$ temperatures in the divertor plasma. These $1 \mathrm{eV}$ temperatures have been measured at the divertor plates and in a large volume of divertor plasma. Estimates that about 50\% of the plasma ions recombine before reaching the divertor plate have been made from direct spectroscopic evidence for recombination. Figure 1 above is a picture of a plasma in DIII-D with the radiation near the divertor plate dominantly from hydrogenic processes, the recombining plasma. Pressure drops along the field lines occur in these plasmas, giving rise to the term "detached plasma." Generally, it is seen that while the separatrix field line becomes detached, the plasma remains attached further out in the SOL, leading to the term Partially Detached Divertor (PDD), which is now the ITER baseline approach. Since the peak heat flux occurs along the separatrix, partial detachment suffices to limit the peak heat flux. Many experiments (and the ITER divertor design) are pursuing various approaches for promoting detachment, including domes, gas sources and pumps in the private flux regions, wings, gas box geometries, etc. The optimum approach is not clear yet.

Experiments have been done attempting to increase the concentration of impurities in the divertor to increase the radiation there [16-21]. Theory suggests that if fuel flow down the field lines (which pushes impurities toward the divertor) can overcome the thermal force (which pushes impurities up the temperature gradient), then the impurity concentration can be enriched in the divertor plasma and increased divertor radiation can be obtained. Enrichment in the pumping plenum is most often quoted (and is most relevant for helium exhaust) while divertor enrichment is the relevant quantity for radiation enhancement. There is an apparent mass dependence of the plenum enrichment with helium de-enriched $\eta \sim 0.2$, neon $\eta \sim 1-2$, and recent measurements of argon enrichment from DIII-D and Alcator $\mathrm{C}-\bmod$ of $\eta \sim 17$. These experiments have mostly been done with trace impurity levels. Forced flows down the field lines produce larger values of plenum enrichment, providing at least some circumstantial support for the basic theory. Measurements of flows and flow patterns in tokamaks have only just begun to emerge. The $2 \mathrm{D}$ code calculations show the role of divertor structures in altering flow patterns and impurity concentrations. The problem of divertor design using the detailed divertor geometry to control flow patterns is an area of future effort.

\section{PARTICLE CONTROL}

The situation for helium and fuel exhaust is very favorable for ITER. Adequate rates of helium exhaust have been demonstrated on a variety of tokamaks in a variety of conditions 
(including ELMing $\mathrm{H}$-mode) using a variety of pumping techniques [21-29]. Values of $\tau_{\mathrm{He}}^{*} / \tau_{\mathrm{E}} \sim$ below 15 have been measured in ELMing $\mathrm{H}$-mode, L-mode, Ohmic plasmas, and supershots; generally results have been in the range 4-10. The helium particle diffusivity and heat diffusivities are about equal across the profiles in ELMing $\mathrm{H}$-mode, ELM free $\mathrm{H}$-mode, $\mathrm{VH}$-mode, and L-mode, which means the core transport rates of helium should be adequate in ITER. The helium and electron density profiles are about the same in all the regimes studied; preferential peaking of the helium density should not be a problem. The helium should emerge from the core plasma at an adequate rate in ITER. The issue becomes one of pumping, since deenrichment of helium is generally observed. Enrichment $\eta$ in the range 0.2 to 1.0 has been measured in attached plasmas. $\mathrm{TdeV}$ has measured $\eta=0.2$ in detached plasmas. With an enrichment factor of 0.2 , a fuel gas throughput of $50 \mathrm{~Pa} \mathrm{~m}^{3} / \mathrm{s}$ is required to provide adequate helium exhaust in ITER; a fuel throughput of $200 \mathrm{~Pa} \mathrm{~m} / \mathrm{s}$ is planned, giving a reserve of a factor of four. ITER simulations indicate that a helium partial pressure of about $0.05 \mathrm{~Pa}$ should be produced, compared with at least $0.01 \mathrm{~Pa}$ required. To exhaust $50 \mathrm{~Pa} \mathrm{~m} / \mathrm{s}$ of fuel with ITER's $170 \mathrm{~m}^{3} / \mathrm{s}$ pumping speed, a fuel gas neutral pressure of only $0.3 \mathrm{~Pa}$ is needed in the pump duct; neutral pressures in the range 0.3 to $13 \mathrm{~Pa}$ have been measured in experiments. These pressures indicate some reserve in ITER's ability to obtain the desired exhaust of fuel. Besides these favorable pressure buildup measurements, tokamaks have added active pumps during the EDA. In ELMing $\mathrm{H}$-mode it has proven possible to exhaust the fuel at a sufficient rate to lower the main plasma density a factor of 2 from the normal $\mathrm{H}$-mode level to the L-mode level [30]. It appears a sound physics basis exists for the necessary fuel and helium exhaust in ITER.

\section{EROSION AND EDGE LOCALIZED MODES}

Erosion of divertor and first wall surfaces has been estimated based on a large database of laboratory physical and chemical sputtering measurements on the basic materials envisioned. Such estimates, including melt layer loss from transients, project adequate lifetimes for the ITER divertor; lifetimes of 100-300 discharges are projected for beryllium, 2000-6000 discharges for Tungsten, and 2000-10000 discharges for carbon [31].

However, only a few direct measurements of net erosion have been made in a tokamak and those are in attached plasma operation only. In experiments using the DiMES erosion probe in DIII-D [32], the measured erosion rate exceeds by a factor of ten the predictions of the erosion rate for the conditions of the DIII-D experiment made using the ITER methodology. The DIII-D experimental results do agree with modeling calculations [32]. The factor ten discrepancy may be explained by different redeposition $(0.8$ in DIII-D versus 0.9 assumed in the ITER calculations), and angle dependence of sputtering (factor of 3 difference), and the relative importance of physical sputtering in the higher divertor temperature DIII-D regime compared to chemical sputtering in the lower temperature ITER divertor plasma. Even less net erosion data and model validations exist for low temperature partially attached or detached regimes. More experimental and model validation work is required in the right parameter regimes for ITER.

Anticipated erosion for ELMs remains at the margin for acceptability in ITER. The threshold for erosion for the transient heat flux owing to ELMs is calculated to be approximately $\Delta \mathrm{Q} / t^{-1 / 2} \leq 40 \mathrm{MJ} \mathrm{m}^{-2} \mathrm{~s}^{-1}$, where $\Delta \mathrm{Q}$ is the target plate energy density due to an individual ELM and $t$ is the time for that energy to be deposited [31]. The ELM energy flux must be kept below this level or the divertor plate would be fully eroded in a few discharges owing to the high frequency of these ELM events. The value of the ablation parameter has been estimated by the scaling of four factors from present experiments, (1) the energy loss from the core plasma, $\triangle \mathrm{E}$, during an ELM, (2) the fraction of ELM energy deposited on the target plate, (3) the deposition profile on the divertor target, and (4) the time for the elm deposition. The energy loss in the main plasma due to individual ELMs has been measured in JET, ASDEX-Upgrade, DIII-D and Compass-D and a scaling of this data projects the ELM amplitude on ITER to be in the range 10-30 MJ [33]. This range, taken in conjunction with the experimental data on ELM energy fraction and duration, spans the range from a value for which the type I ELM regime could be operated in ITER to a regime where it could not be operated. Active control methods to lower type I ELM amplitudes would be useful.. The type II and type III ELM regimes are applicable in ITER from an erosion point of view.

\section{NEW DIVERTOR GEOMETRIES}

All of the major tokamaks have made significant modifications to their geometries recently in order to study how divertor geometry details can lead to more efficient power and particle exhaust. Alcator C-mod began operation in 1992 with a fairly closed vertical target. JET began a series of progressively closed pumped divertor experiments with the Mark I (1994-95), and Mark IIA (1996-97), and plans to install the Mark II GB beginning January 1998. ASDEXUpgrade operated from 1992-1996 with a moderately closed divertor (Div. I), and began operation with a deeper, more baffled vertical target divertor (Div. II, the "LYRA") in June 1997. TdeV recently studied the effect of divertor geometry on Helium exhaust. DIII-D has recently installed only the upper outer baffle and pump (phase RDP-1a) of their planned highly baffled, pumped double null divertor. JT-60U has installed a W-shaped divertor which began operation in late spring of 1997. The JFT2-M group has carried out a sequence of experiments with increasing divertor closure. Some of these divertor modifications are shown in Fig. 2. The data from these experiments should form a basis for later stage divertor modifications in ITER. 

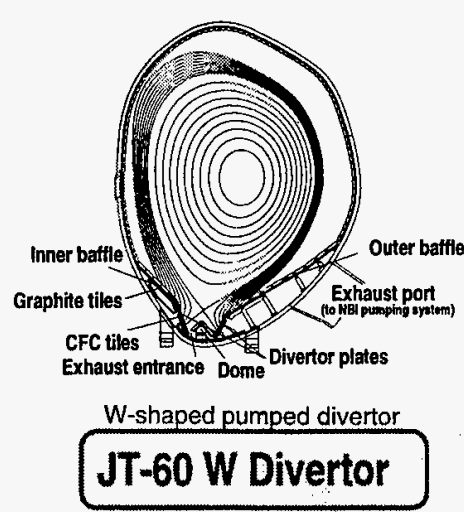
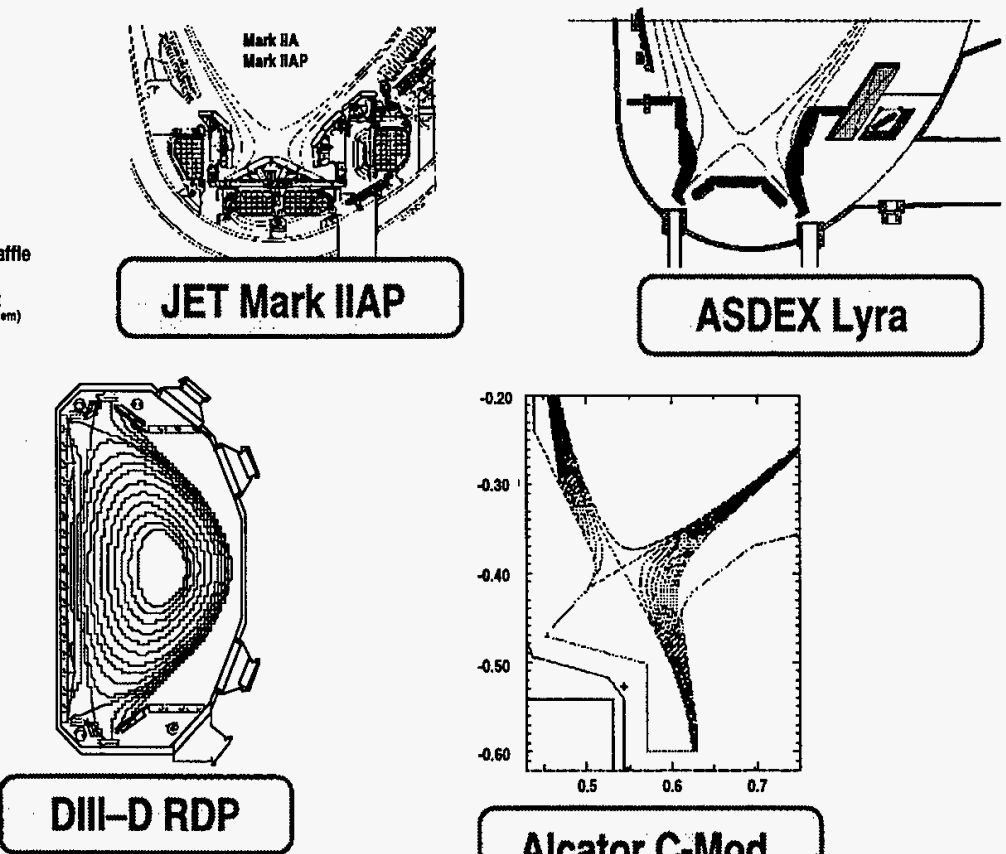

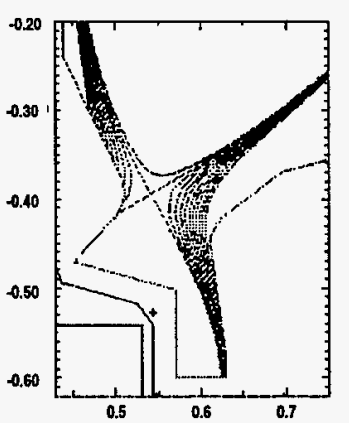

Alcator C-Mod

Fig. 2. New divertor geometries.

\section{CONCLUSION}

Tremendous advances in divertor physics have occurred in the last few years. The most prominent such advance has been the thorough documentation of detached plasmas with high degrees of recombination. There is a sound experimental and computational basis for ITER's nominal power balance position and possible movement in the direction of higher core radiation. More research needs to be done to find more highly radiative divertor operating modes. Helium exhaust appears to be well in hand for ELMing $\mathrm{H}$-mode. Erosion estimates project adequate surface lifetimes, but more data from tokamak experiments is needed. We are only a factor of two away from acceptability for all three ELM regimes in ITER.

\section{ACKNOWLEDGMENT}

The author wishes to acknowledge that the summary given in this paper reflects material contributed by the members of the ITER Divertor Expert Group at various Expert Group Meetings in the last four years; however the interpretations presented are solely the responsibility of the author. Members of the ITER Divertor Expert Groups are: Japan [N. Hosogane, K. Itami, N. Ohyabu, M. Shimada (chair), S. Takamura, H. Tawara], EU [A. Loarte, J. Neuhauser, D. Reiter, G. Vlases, J. Winter], US [B. Braams, S. Cohen, C. Karney, S. Krasheninnikov, B. Lipschultz, G. Porter, T. Rognlein], Russia [V. Abramov, A. Pigarov, A. Pozharov], JCT [F. Perkins, D. Post (co-chair), S. Putvinski, M. Sugihara].

\section{REFERENCES}

[1] G. Janeschitz et al., "ITER divertor, pumping and fueling system designs," in Fusion Energy (Sixteenth Conference Proceedings, Montréal), vol. 2, 1996, p. 755.

[2] H.S. Bosch et al., Plasma Phys. Contr. Fusion, vol. 38, 1996, pp. 1493-1496.

[3] G.F. Matthews et al., J. Nucl Mater., vol. 241-243, 1997, pp. $450-455$.

[4] ITER Detailed Design Description Document, 1997.

[5] A. Messiaen, Phys. Rev. Lett., vol. 77, 1996, p. 2487 and Phys. Plasmas, vol. 4 ,1997), p. 1690.

[6] A.W. Leonard et al., Phys. Rev. Lett., vol. 78, 1997, p. 4769 and "Radiative divertor plasmas with convection on DIII-D," APS-DPP invited talk, 1997, to be published in Phys. Plasmas.

[7] G.C. Vlases et al., "Effect of divertor configuration on plasma performance in JET,' in Fusion Energy (Sixteenth Conference Proceedings, Montréal), vol. 1, 1996, p. 371.

[8] K. Itami et al., "Radiative divertors with improved core plasma confinement in JT-60U,'” ibid., p. 385.

[9] B. Lipschultz et al., "Variation of the divertor geometry in Alcator C-Mod,"' ibid., p. 425.

[10] D. Post et al., "Analytic criteria for power exhaust in divertors due to impurity radiation," $J$. Nucl. Mater., vol. 220-222, 1995, p. 1014.

[11] G.D. Porter et al., Phys. Plasmas, vol. 3, 1996, pp. 1967-1975.

[12] S.I. Krasheninnikov et al., Phys. Plasmas, vol. 4, 1997, p. 1638.

[13] A. Loarte, to appear in J. Nucl. Mater., 1997.

[14] D. Lumma et al., Phys. Plasmas, vol. 4, 1997.

[15] V. Mertens et al., "“Edge and divertor physics in ASDEX Upgrade with emphasis on density limit characteristics," in Fusion Energy (Proc. 16th Int. Conf., Montréal), vol. 1, 1996, p. 413. 
[16] M.R. Wade et al., "Impurity enrichment studies with induced scrape-off layer flow on DIII-D," General Atomics Report GA-A22698, 1997, submitted to Nucl. Fusion.

[17] M.J. Schaffer et al., Nucl. Fusion, vol. 8, 1995, p. 1000.

[18] M.J. Schaffer et al., J. Nucl. Mater., vol. 241-243, 1997, p. 585.

[19] J. Neuhauser et al., J. Nucl. Mater., vol. 121, 1984, p. 194.

[20] D.P. Coster et al., J. Nucl. Mater., vol. 241-243, 1997, p. 690.

[21] G.W. Pacher et al., "Effect of divertor geometry and plasma density on helium enrichment on TdeV-96," to appear in Proc. 24th EPS Conf. on Controlled Fusion and Plasma Physics, Berchtesgaden, 1997.

[22] M.R. Wade et al., "Helium transport and exhaust studies in enhanced confinement regimes in DIII-D," Phys. Plasmas vol. 2, 1995, p. 2357.

[23] H.S. Bosch et al., "Particle exhaust in radiative divertor Experiments, J. Nucl. Mater., vol. 241-243, 1996, p. 82.

[24] D.L. Hillis et al., Phys. Rev. Lett., vol. 65, 1990, p. 2382.

[25] H. Nakmura et al., Phys. Rev. Lett., vol. 67, 1991, p. 2382.
[26] M. von Hellermann et al., "Helium and neon transport experiments in JET,' in Proc. 22nd EPS Conf. on Controlled Fusion and Plasma Physics, Bournemouth, vol. 2, 1995, p. 9.

[27] A. Sakasai et al., "Helium transport during H-mode in JT60U," in Proc. 20th EPS Conf. on Controlled Fusion and Plasma Physics, Lisbon, vol. 1, 1993, p. 67.

[28] M.R. Wade et al., "Helium exhaust studies in the DIII-D tokamak, J. Nucl. Mater., vol. 220-222, 1995, p. 178.

[29] H.-S. Bosch et al., "Particle exhaust studies in ASDEX Upgrade,' submitted to Plasma Physics and Controlled Fusion, 1997.

[30] M.A. Mahdavi et al., "Divertor heat and particle control experiments on the DIII-D tokamak, J. Nucl. Mater., vol. 220-222, 1995, p. 13.

[31] H.D. Pacher et al., J. Nucl. Mater., vol. 241-243, 1997, p. 255.

[32] D.G. Whyte et al., J. Nucl. Mater., vol. 241-243, 1997, p. 660.

[33] A.W. Leonard et al., "Divertor heat and particle flux due to ELMs in DIII-D and ASDEX-Upgrade," J. Nucl. Mater., vol. 241-243, 1997, p. 628. 


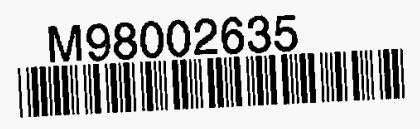

Report Number (14)GA--A 22794

CONF-971065-

Jubl. Date (11)

Sponsor Code (18)

199801

JC Category (19)

$\frac{D O E / E R, X F}{U C-2400, D O E / E R}$ 